\title{
Embodied practices of prosthesis
}

\author{
By Maria Bee Christensen-Strynø \& Camilla Bruun Eriksen
}

\section{Abstract}

While the prosthesis is often thought of as a technology or an artefact used to 'fix' or make 'whole' a disabled body, it has also become an important figuration and metaphor for thinking about disabled embodiment as an emblematic manifestation of bodily difference and mobility. Furthermore, the ambiguity and broadness of prosthesis as an object and a concept, as well as its potential as a theoretical and analytical thinking tool, show up in widely different areas of popular culture, art and academic scholarship. In this article, we explore the opportunities of the ways in which prosthesis might be a helpful and productive figure in relation to framing, analyzing and understanding certain healthcare-related practices that are not traditionally associated with disability. Our aim is to suggest new ways of building onto the idea of the performative value of the prosthetic figure and its logics as a continuum through which very different forms of embodied practices could be meaningfully understood and analyzed. Thus, we argue that the logic of the prosthesis can be helpful in uncovering tensions related to idealistic and dominant ideas about health and embodiment. First, we engage with the theoretical discussions from cultural studies, including critical disability studies, in which we broaden the scope of the concept of prosthesis. Second, we introduce and discuss two illustrative case examples in the form of dance therapeutic practices for people with Parkinson's disease and group therapeutic practices in male-friendly spaces. In doing so, we seek to raise new questions about the ongoing cultivation of bodily and health-related interventions through the lens of the prosthetic spectrum, which we have labelled embodied practices of prosthesis.

KEYWORDS: Prosthesis, embodied practices, disability, therapeutic and healthcare-related interventions.

MARIA BEE CHRISTENSEN-STRYNØ, postdoctoral researcher, Department of Communication and Arts, Roskilde University.

CAMILLA BRUUN ERIKSEN, assistant professor, Department for the Study of Culture, University of Southern Denmark. 


\section{Introduction: Setting up the interrogation}

Back in 2014 the Latvian-British pop artist Viktoria Modesta released the music video Prototype produced specifically for British Channel 4's disability media awareness-raising campaign Born Risky.1 "Forget what you know about disability", the campaign told us, "Some of us were born to be different. Some of us were born to take risks". Throughout the video, Modesta is, much like any other fashionable and replaceable accessory, 'wearing' a number of noticeable prosthetic legs; one is a black metal spike, another is fluorescent and lights up, and a third is covered in sparkling crystals. The video's mixture of both fleshly and prosthetic body parts, shifting costumes, dancing ensembles, fashion excess and exclusivity, not only reminds us - as is intended - that being born (or becoming) disabled can be negotiated in creative ways, or that bodily diversity should be considered a location of originality. But also, that an object like the prosthesis does not exist outside of mainstream consumption or pop-cultural consumerism, and rather than being merely an addition to a human body, it may even extend into other areas of our cultural imaginations. This is, for instance, demonstrated by Danish artist Jesper Just who in the summer of 2019 presented the exhibition Servitudes at Kunsthal Charlottenborg. ${ }^{2}$ The exhibition, an architectural installation, consisted of eight synchronized nine-minute films on a loop revolving around three characters of which one was "the iconic One World Trade Center in New York, a prosthesis of the city and a phantom limb occupying the void left by the traumatic loss of the Twin Towers" (Kunsthal Charlottenborg 2019). Using the prosthesis, Just investigates concepts like agency, hybridity and (dis)ability and in doing so, attempts to blur the lines between machines and organisms, fiction and experience (Ibid.).

Both Modesta's music video and Just's art installation present us with expansive versions of what prosthesis might be or signify, showing off the ambiguity and broadness of prosthesis as an object and a concept, as well as its potential as a theoretical and analytical thinking tool. As already noted by Maria Bee Christensen-Stryn $\varnothing$ (2016), Modesta's use of prosthetics in her video is an illustrative example of how popular cultural imagery of, in this case, disability can serve as both a form of resistance as well as incorporation; a point we will return to and wish to explore further in this article by paying special attention to the prosthesis - or what we are calling embodied practices of prosthesis.

While the prosthesis has been (and often still is) thought of as a technology, or an artefact, used to 'fix' or make 'whole' a disabled body, it has also (quite contrarily) proven useful for critical disability scholars in contesting "the illusion of an originary unified and singular body, exposing instead the fluidity of categorical boundaries [and raising] fundamental questions about the hybrid nature of intercorporeality" (Shildrick 2017: 142). As such, the prosthesis within critical disability studies has become an important figuration and metaphor for thinking about disabled embodiment as an emblematic manifestation of bodily difference and mobility not only in the sense of confinement and limitation (Campbell 2009; Sawchuk 2013), but also as possible transgressions and expansions of normative bodily functionality as well as the somatechnic interventions and alterations shaping our everyday lives (Cadwallader \& Murray 2007; Shildrick 2015; Sullivan \& Murray 2009).

In this article, we explore the opportunities of the ways in which the prosthesis might be a helpful and productive figure in relation to framing, analyzing and understanding communal healthcare-related practices that are not traditionally associated with disability. While our aim here is to broaden the scope of the concept of prosthesis in ways that can help us uncover tensions related to dominant and idealistic conceptions and notions of health and embodiment, we are also deeply aware of the potential pitfalls of extending the concept of prosthesis. Therefore, we want to make clear from the beginning that our intention is not to argue for an all-encompassing universal understanding of the prosthetic concept. Rather the aim of this article is to consolidate the critical value of the concept and its embeddedness within a disability theoretical framework, and thus its 
indisputable connections to the lived experiences of (some) disabled people, while also suggesting ways of building onto the idea of the performative properties of the prosthetic figure and its logics as a continuum through which very different forms of embodied practices could be meaningfully understood and analyzed.

Through our current work on two different research projects, ${ }^{3}$ we have become particularly concerned with tensions occurring in the developments and formations of collective therapeutic practices and prevalent ideas and discourses of health, treatment and cure, which in many aspects seem to manifest themselves as performative enactments through specific logics deriving from the concept of the prosthesis. Drawing on our research fields through two illustrative case examples, dance therapeutic practices for people with Parkinson's disease and group therapeutic practices in male-friendly spaces, we also, in turn, hope to show how these logics interestingly emerge as blurry tensions of binary relations between notions of conformity and resistance as well as extension and integration.

We start out by engaging with the theoretical discussions of the prosthesis that have taken place within cultural studies, including in critical disability studies, in order to flesh out and later on attempt to broaden the scope of the concept of prosthesis. Next, we introduce and discuss our two illustrative case examples and in doing so seek to raise new questions about the ongoing cultivation of bodily and healthcare-related interventions by activating the performative properties of the prosthesis as an analytic lens.

\section{What is in a word?}

The term prosthesis is used to describe the "replacement of a missing part of the body with an artificial one" and first appeared in medical texts in the early eighteenth century (Wills 1995: 215). However, the use of different tools and mechanical aids to enhance bodily functionality is, of course, much older and not solely correlated to medicine. A point taken up by Elaine Scarry in The Body in
Pain: The Making and Unmaking of the World (1985) in which she argues that all artefacts in some way or other recreate and extend the body. Following the work of Scarry, Ellen Lupton and Abbott Miller have pointed out that while many of us might not grant it much thought in our everyday use of such objects, "[c]hairs supplement the skeleton, tools append the hands, clothing augments the skin" (1996: 9). As such, "[f]urniture and houses are neither more nor less interior to the human body than the food it absorbs nor are they fundamentally different from such sophisticated prosthetics as artificial lungs, eyes and kidneys" (Ibid.). Keeping in mind, then, that bodily materiality is always vulnerable and inscribable, all bodies are, in different ways, prostheticized. Some bodies, however, are more closely linked to and associated with prosthesis - especially those marked by disability. As underlined by disability scholars David T. Mitchell and Sharon L. Snyder prostheses are constituted within a regime of tolerable deviance: "If disability falls too far from an acceptable norm, a prosthetic intervention seeks to accomplish an erasure of difference altogether; yet, failing at that, as is always the case with prosthesis, the minimal goal is to return one to an acceptable degree of difference" (2000: 7). Often put forward as an obvious, indisputable and necessary 'solution' to a body deemed lacking and/or unfunctional, the prosthesis carries with it notions of lack, compensation, correction and normalization. Thus, within a framework of rehabilitation and therapy, the prosthesis holds the promise of a 'return to normal'.

Since its first appearance in medical texts the prosthesis has been taken up by a wide range of scholars and is now an interdisciplinary term used in vastly different ways. An example of this is feminist scholar and writer Audre Lorde's use of the prosthesis in her discussions of empowerment, subjectivity and resistance. In the third and last chapter of The Cancer Journals (1980) entitled "Breast Cancer: Power vs. Prosthesis", Lorde centers her writing around the question of whether or not to attempt to normalize her post-surgical body by wearing breast prostheses after her double mastectomy. Underlining that such a decision is always a personal one, Lorde herself posits that 
the breast prosthesis is a societal misogynist cover-up reducing women to a matter of physical appearance. In framing the prosthesis as a problematic 'quick fix', Lorde simultaneously deconstructs notions of healing and reconstruction therapy and in doing so bids a powerful critique of the way a prosthesis, according to her, inherently offers the meaningless comfort of "nobody will know the difference" (Ibid.: 53, emphasis added). For Lorde, then, the prosthesis is firmly intertwined with feminist politics of visibility, silence and the body, and her writing on the matter has inspired a large (and still growing) body of related work (e.g. Al-Zubi 2007; Crompvoets 2012; Herndl 2002; Major 2002; Reiffenrath 2016; Waples 2013).

In a similar vein, in terms of the politics of visibility, is Mitchell and Snyder's use of the prosthesis in their investigations into the traditions of cultural representation of disability. In their highly influential book Narrative Prosthesis. Disability and the Dependencies of Discourse (2000), the two authors develop a narrative theory of the discursive dependency on disability in literature and film, asserting that "disability has been used throughout history as a crutch upon which literary narratives lean for their representational power, disruptive potentiality, and analytical insight" (2000: 49). According to Mitchell and Snyder, "[t]he very need for a story is called into being when something has gone amiss with the known world, and, thus, the language of a tale seeks to comprehend that which has stepped out of line. In this sense, stories compensate for an unknown or unnatural deviance that begs an explanation" (Ibid.: 53). As such, stories tend to follow a specific pattern: First, a difference is exposed which, secondly, calls for an explanation that, thirdly, continues to bring difference to the forefront of the story before, lastly, the difference can be 'fixed' and the story brought to an end (Ibid.) For Mitchell and Snyder, the prothesis makes possible an analytical framework for critical interpretations of cultural representations of disability.

Lastly, a popular take on prosthesis, perhaps not surprisingly, are writings on and theorizations of the prosthesis lacing together bodies and technology (e.g. Christie \& Bloustien 2010; Goggin \&
Newell 2005; Reeve 2012; Shildrick 2017), as is the case with the emerging field of somatechnics grounded in the position that bodies and technologies do not exist outside of, or separate from, one another as bodily being "is always already technologized, and technologies are always already enfleshed" (Sullivan \& Murray 2009: 7). Using the prosthesis both as metaphor and specific empirical point of entry, disability and somatechnical scholar Margrit Shildrick has worked extensively on boundaries of embodiment:

As I understand it, it is in the nature of prostheses to effect powerful transformations to the embodied subject that move beyond mere modification towards the far more radical step of rethinking the limits of the human. As both troubling and productive, in invoking an inevitable hybridity, those supplements to the human body raise the question of discrete corporeal boundaries to another register (2013: 271).

Akin to Shildrick's somatechnical thinking, scholars like Elizabeth Grosz as well as Donna Haraway have in their ground-breaking works (respectively: Volatile Bodies: Toward a Corporeal Feminism (1994) and "Situated Knowledges: The Science Question in Feminism and the Privilege of Partial Perspective" (1988)), used the prosthesis as a metaphor for comprehending and unfolding the different ways in which science and technology shape and are shaped by our bodies.

\section{Contesting the cultural imaginations of prosthesis: Not feeling posthuman}

Along with the gradually expanded conceptual and theoretical interests in prosthesis, especially in the fields of cultural theory and arts-based research (e.g. Garoian 2013; Grosz 1994; Mitchell \& Snyder 2000; Shildrick 2013, 2015, 2017), there has also been a number of critics voicing their concerns with these, in some instances, very broad definitions of and approaches to prosthesis. In slightly crude terms, Katherine Ott asserts that much work 
from cultural theory has promoted inaccurate and erroneous definitions of prostheses (2002: 2f.). As a curator of medical science and located within a scholarly context of history, one could easily write off Ott's criticism as being rooted in a strong disciplinary positioning of prosthesis in her own particular field of research. Yet, the critical stances toward the ampler theorizations of the prosthesis are also echoed within frameworks of cultural studies. As Vivian Sobchack notes in an account of her own lived experience of being an amputee living with a prosthetic leg:

When I put my leg on in the morning, knowing that I am the one who will give it literal (if exhaustible) vitality even as it gives me support, I don't find it nearly as seductive a matter - or generalized an idea - as do some of my academic colleagues (Sobchack 2006: 17).

Being a media and cultural theorist herself, Sobchack expresses an internal skepticism towards a tendency of sensationalizing 'the prosthetic' through its elusive metaphorical value, which she calls "a tropological currency for describing a vague and shifting constellation of relationships among bodies, technologies, and subjectivities" (Ibid.: 19). With reference to Sarah S. Jain (1999), who has investigated the trope of prosthesis within a framework of science and technology studies' fascination with human-technological relationships and boundaries, Sobchack points out that the concept of prosthesis in most disciplines (except in disability studies) has been blurred to such a degree that the literal and material connections of prosthesis to lived embodied experience have been entirely forgotten (Sobchack 2006: 20). In this sense, Sobchack also reiterates Ott's criticism that "[c]yborg theorists who use the term 'prosthesis' to describe cars and tennis rackets rarely consider the rehabilitative dimension of prosthetics, or the amputees who use them" (Ott 2002: 3).

The criticism of contemporary uses and conceptualizations of prosthesis in such academic settings thus reminds us that prosthetic realities are, in fact, still made up of people who, in
Sobchack's words, "actually use prostheses without feeling 'posthuman' and who, moreover, are often startled to read about the hidden powers that their prostheses apparently exercise both in the world and in the imaginations of cultural theorists" (2006: 20). However, despite placing important critiques of the imprecise and disembodied notions of the prosthesis, the critical voices offered by Sobchack and others still resonate with the idea that the experiences of wearing, using and living with prostheses challenge and broaden how we think about embodied practices of our everyday lives. Sobchack acknowledges that the convergence of fleshly and synthetic bodily materiality (as well as phantom limbs - see Sobchack 2010), allows the body to be re(con)figured into new 'ensembles' that are "organically related in practice" (Sobchack 2006: 26, emphasis in the original), which might even be the cause of an extended or heightened bodily awareness (Ibid.: 32).We shall return to this particular idea later on in relation to our two case examples.

As such, the retention of the prosthesis in relation to the lived experiences of material bodies is not in opposition to the thought that some form of 'prosthetic logic' exists along the lines and is representative of, for instance, the somatechnic interventions and augmentations of our everyday lives. As noted by Shildrick:

The current fascination with and critique of the prosthetised body arises not from any sudden change which would demand radical reconfigurations of the concept of human corporeality, but rather from the ubiquity and availability of technological interventions into the body that have pushed the issue into lay consciousness (Shildrick 2013: 271).

Rather than merely encouraging bizarre cyborgian abstractions as explanations for a technologized-driven society, it is, according to Shildrick, possible to understand the prosthesis as a critical approach to rethinking human hybridity in ways that have also gained a certain everyday ordinariness and recognizability; one that does not necessarily cancel out the subjective and lived 
experiences of human corporeality. While not uncomplicated, we find this observation of prosthetic 'commonplaceness' to be especially intriguing for reasons that we will now endeavor to explore as forms of embodied practices of prosthesis.

\section{Testing the waters: Embodied practices of prosthesis}

In continuation of the conceptual developments and the criticisms thereof, our aim in this article is to further an understanding of the prosthesis by suggesting that the broadened recognition and popularization of prosthesis (in its sum of being a figure/trope/metaphor/material object/theoretical concept) may also hold a productive potential to be explored and understood through its performative properties in relation to the embodied experiences and expressions in certain healthcare-related practices. These, we detect, resonate both with the theoretical discussions of bodily lack, replacement and enhancement, as well as with tangible human bodies involved in processes of rehabilitation and therapeutic interventions.

Our framing of the prosthesis in relation to these health-oriented practices builds on performativity theory as developed by (amongst others) Judith Butler. Butler's highly influential work on performativity and subjectivity calls into question the existence of boundaries between material and immaterial entities by instead suggesting performativity as a form of repeated stylization involving a myriad of acts that "congeal over time to produce the appearance of substance, of a natural sort of being" (Butler 1990: 33). Thinking along these same lines, we want to suggest that the prosthesis can be viewed as an 'entity' performatively constituted within and through the rigid and regulatory processes of recognition governed by norms and power.

By explicitly reframing the prosthesis through its performative properties it suddenly also becomes a matter of prosthetic enactments in which something apparently much more mundane than an artificial limb, such as therapeutic dancing, could emerge as a prosthetic practice.
This suggestion is, of course, an abstraction from the conventional notion of the prosthesis as merely a physical object. Yet, as we have discovered from delving into the many theoretical discussions of prosthesis, it is a concept resting upon ambiguous logics which often seem to find legitimization in both rehabilitative, therapeutic and normalizing functions, as well as in the ability to expand and enhance non-conventional ways of embodied being (e.g. Booher 2010). While this exact tension, or what we could call the equivocal logic of the prosthesis, may find its paragon expression in traditional prosthetic devices, we have also become more and more aware of the performative complexities of prosthetic logics present in certain forms of health-oriented practices.

We are aware that our suggestion of instrumentalizing the prosthesis through its performative properties, and hereby also allowing it to be viewed as a set of extended embodied practices, thus continues to be in an exposed position of being rejected as yet another 'casual abstraction', especially because none of our illustrative case examples are directly connected to bodily experiences of the presence and absence of (non-)fleshly human limbs. Nevertheless, we hold that the productive potential of broadening the scope of the concept of prosthesis has a significant analytical value while we, at the same time, wish to stay sensitive towards not trivializing and diminishing the real-life narratives of amputees and their embodied experiences. In other words, we wish to show that an understanding of the prosthesis as neither simply 'disembodied metaphor' nor 'everyday-embodied-technology' but instead as a set of social and performative practices, or collective doings, makes the ambiguous yet productive capacity of the concept of the prosthesis intelligible. As we shall see, then, our examples both (re)produce the prosthesis' normalizing form and hold the potential to resist prevailing understandings of how health should be embodied; a process we have named embodied practice of prosthesis.

Furthermore, our motivation for highlighting the productive potential of the concept of prosthesis has additional implications which are related to the cultivation of the field of critical disability 
studies and its 'tool-box treasuries'. Therefore, we think it would be helpful to understand why we decided to write this article in the first place. Both of us, the authors of this text, position ourselves within or with close ties to the field of critical disability studies (see e.g. Christensen-Stryn $\varnothing 2018$, 2020; Christensen-Stryn $\varnothing$ \& Eriksen 2020; Eriksen 2017), but - as is the case for many disability scholars - we are also situated within interdisciplinary research contexts and communities of cultural, media and communication studies, through which our approaches to and through disability are continuously shaped and adjusted. Our locations in academic settings that are, more often than not, grounded in areas that do not have specific disability-related entry points and frameworks (which is also the case in our current research projects), have taught us to think through critical disability perspectives as a productive prism for in-depth scrutiny of the intersections of bodily and embodied aspects of privilege, marginalization and power dynamics that apply to a wide range of social contexts and practices. In this sense, we firmly believe that critical disability studies as a discipline, as well as its developments of theoretical discussions of specific concepts such as prosthesis, compels us to pose questions that sometimes reach far beyond the scope of disability as a category in and of itself.

Dan Goodley states that "[c]ritical disability studies start with disability but never end with it: disability is the space from which to think through a host of political, theoretical and practical issues that are relevant to all" (Goodley 2013: 632). Following Goodley, we believe that while the concept of prosthesis may be inseparably linked to certain forms of disabled embodiment, its inherent logic also extends to and allows us to raise critical discussions about other and more normative forms of embodied practices, even if these are only inpart, or not at all, directly associated with disability. More precisely, by accepting the performative properties of the prosthesis as ubiquitous regulatory embodied processes, it becomes a concept that concerns most (if not all) of us, rather than a few. A broadened conceptualization of prosthesis as an integral part of regular embodied practices could thus serve as a critical lens for understanding some of the inner workings of not only particular forms of disability, but also more general therapeutic and rehabilitating practices as represented in our two case examples. Consequently, a primary motivating factor for writing this article is to stress the importance and relevance of critical disability theoretical frameworks and concepts for broader discussions of our everyday social realities.

That being said, we are not interested in the theoretical exercise of applying the concept of prosthesis to just any everyday social practice. As mentioned, our current work on two different research projects has confronted us with particular tensions that occur in the developments and formations of collective therapeutic practices and prevalent ideas and discourses of health, treatment and cure. While of course different from each other in a variety of ways, the two examples do share similarities that we believe make them interesting as prosthetic enactments. Most obvious perhaps, they are both examples of therapeutic and rehabilitative inspired social practices taking place within collective communities with close ties to contemporary and normative notions of health and embodiment. ${ }^{4}$

To sum up, we believe that a broadened conceptualization of prosthesis as an integral part of certain health-related practices holds a productive potential not only in relation to disability, but also when exploring forms of embodiment involved in more general therapeutic and rehabilitating practices as represented in the following two case examples.

\section{Dance therapeutic practices for people with Parkinson's disease}

In recent years therapeutic dancing classes and related forms of arts-based therapies in relation to Parkinson's disease (PD) have increased in popularity (Aguiar et al. 2016; Hackney \& Bennett 2014; Houston 2019; McGill et al. 2014). Research indicates that dance may help to delay or slow down the development of symptoms of PD, while another emerging perspective is the experiences 
of dance as a valued social activity among people living with PD (Houston 2019; Parkinson s.d.).

Reading PD-related dance activities through the lens of prosthetic logics initially draws the attention towards, on the one hand (or another optional limb), the utilizable and technical qualities of dancing as a 'prosthetic crutch', reflecting the compensatory and rehabilitative properties of a prosthetic device. On the other, there are the obvious indications of further considering the questions whether the practice of dance extends, modifies and ultimately changes people with PD's bodies and minds in new ways, especially through the social and artistic dimensions of dancing together. Although this may at first seem a rather simplified transference of prosthetic logics to the areas of PD and dance, these are, in fact, what we would consider to be the main qualifying markers of an embodied practice of prosthesis. Yet, in order to flesh out this idea more thoroughly, and to offer a more complex analytical understanding, we will seek to address the composite entanglements of the prosthetic properties in relation to PD and dance as an emerging social activity which seem to latch onto broader discussions of established notions and norms about health and embodiment.

People with PD are diagnosed within the context of neuropathology, and the progressions of illness are primarily managed through medical healthcare (Parkinson s.d.). However, the PD diagnosis, which is broadly categorized as a chronic neurodegenerative condition, known to affect the motor system in different ways and over time, is not easily characterized by uniform courses of illness and treatment. Rather the diagnoses and treatments are informed and framed by unpredictable progressions of a variety of symptoms, such as tremors, rigidity and slowness, and a life course possibly affected by a wide range of accompanying health conditions. Consequently, areas of non-medical healthcare in relation to PD have also been given increased attention, primarily through physiotherapeutic guided exercising (Ibid.). In Denmark, Parkinsonforeningen (The Parkinson's Association) encourages people with PD to exercise on a regular basis which is based on the reasoning that people with PD are at a much greater risk of becoming physically inactive, and which, as it is articulated on the association's website, may cause various 'lifestyle' diseases and, furthermore, may lead to social isolation and loneliness (Ibid.). In this sense, the non-medical perspective of PD treatment correlates strongly to the biomedical area of focusing on counteracting physical deterioration, but it also accentuates the social consequences and underlying social norms of living with a chronic health condition as PD.

Highlighting the dual logic in the non-medical treatment of PD might seem quite trivial but is important to recognize as this attitude also flows into the ways in which dance is being positioned in the discourse of PD treatment. Although dance is framed, first and foremost, as a social activity intended to create shared experiences of joy (Ibid.) by linking aesthetic values to well-being (Houston 2019), it also, at least in part, seems to find its validation in the direct effects it might have on relieving physical symptoms of PD. This, for instance, becomes quite clear from interviewing PD dancers about their personal experiences with dancing, ${ }^{5}$ as many of the interviewees chose to highlight that through dance they experience reductions of tremors and improvements in fine motor skills. Parts of these self-narrations seem to be closely connected to dominant ideas and guidelines about health as obtained through treatment and bodily intervention. From this point of view, the connection to the aiding properties of the prosthesis does not seem too far out of sight. Thus, it also becomes more obvious that the act of dancing, as well as dance as a discipline and an art-form, have tool-like characteristics that work in disciplinary and stabilizing ways. Furthermore, and with Lorde's (1980) understanding of 'the prosthetic quick-fix' in mind, dance and dancing as a form of rehabilitating therapeutic practice for people with PD seems to be profoundly entwined with ideas about maintaining or 'returning to normal' through a common understanding of dance as a social practice that is not traditionally associated with illness. However, whereas Lorde emphasizes the oppressive consequences of prosthetic cover-ups, it could also be argued that the 'return to normal' 
in relation to PD dance might lead to other less despondent conclusions.

As opposed to physiotherapeutic exercising, which is medically recommended and made eligible for subsidy in PD healthcare treatment in Denmark, dance as a social practice upholds a position of being a chosen activity. While also a complicated policy issue, the important point to be made here is that the practice of dancing, to some extent, signals independence and autonomy. Not only is the dancing PD body given an opportunity to reclaim an identity not entirely tied to medically informed understandings of illness, it is also allowed to regain an everyday experience of agency and control with individual preferences and values, for instance, of aesthetic pleasure and artistic performance. This perspective thus reflects the 'enhancing' qualities of dance as an embodied practice of prosthesis, as well as its possible social transformative potential. Returning to Sobchack's appreciation of her body as an 'organic ensemble' in which her prosthetic leg has made her "more not less - intimate with the operation and power of [her] body" (2006: 32), we might also come to think about the ways in which the dancing PD bodies acquire new forms of strengths, skills and sensory awareness, even if these are also deeply rooted in biomedicalized needs and desires for rehabilitation and cure.

\section{Group therapeutic practices in male- friendly spaces}

Originating from Australia in the mid-1990's, the now international and non-profit organization Men's shed operates on a local level promoting social interaction and community building with the overall aim of increasing men's quality of life (see e.g. Golding 2015; Ford, Scholz \& Lu 2015). Organized in Denmark by the Forum for Mænds Sundhed (Men's Health Forum), the social meeting places called Mænds Mødesteder (Men's meeting sites) are part of the organization's two-fold ambition: To support knowledge sharing between scientists, clinicians, therapists and health workers invested in men's health, diseases and well-being, and to participate in a wide range of activities that focus on and aim to raise awareness of men's health (Forum for mænds sundhed, s.d.). The very existence of a highly popular organization like Men's shed along with others (e.g. global NGO Movember and Men's shed's own sub-project Spanner in the Works, ${ }^{7}$ both designed to encourage men to learn about health and seek regular medical check-ups) points to and supports a common notion that men's health is, in fact, in crisis and in dire need of attention. A recent report by the World Health Organization (WHO) backs this claim in stating that men, compared to women and across categories such as socioeconomic status, sexuality, race, ethnicity and age, access primary care health services less frequently, are less involved in preventive initiatives and health promotion and are less health-literate (WHO 2018: 66).

According to Mitchell and Snyder it is exactly the perception (real or not) of a 'crisis' or 'special situation' that historically has made disabled people the subject of governmental policies and social programs aimed at 'fixing' bodily as well as mental and cognitive 'shortcomings' (Mitchell \& Snyder 2000: 47). While it is not our intention to collapse the two categories by arguing that men - qua their 'inability' compared to women to seek help and talk about their feelings - should be considered disabled, we want to draw attention to the similar 'special situation' or even 'crisis' created around notions of men's health in recent years. By framing men's health as lacking and in crisis the possibility as well as need for intervention is established and thus, much like was the case of PD, a seemingly non-medical initiative like 'male friendly spaces' easily and neatly aligns itself with broader biomedical logics of 'prevention' and 'treatment' invested in curbing mental illnesses. Thus, a 'male-friendly space' like the shed can be thought of as a therapeutic and rehabilitative space constituted by the social interactions and activities taking place within in but also, with our embodied practice of the prosthesis in mind, as a prosthetic device or 'crutch' used to, if not 'fix', then perhaps optimize or enhance what is framed by Men's shed as an uncultivated potential in men('s health). Aimed at helping men 'deal' with, or perhaps even learn for the first time how to better manage, 
their health, Men's shed stresses the generally positive outcome of 'male-friendly spaces' but also the vital impact such therapeutic spaces can have on men's lives:

\begin{abstract}
Sheds are about meeting like-minded people and having someone to share your worries with. They are about having fun, sharing skills and knowledge with like-minded people and gaining a renewed sense of purpose and belonging. As a by-product of all of that they reduce isolation and feelings of loneliness, they allow men to deal with mental health challenges more easily and remain independent, they rebuild communities and in many cases, they save men's lives (Men's shed s.d.).
\end{abstract}

While the biopolitical and normalizing potential of the prosthesis in regards to the management of health might be hard to overlook, it is also possible to think about such acquired practices (like talking about one's feelings with others) as something that extends one's abilities not just on an individual level but also through the simultaneous reconfiguration of traditional masculinity ideals. Thus, the description of what a shed 'is about' quite accurately points to the ambiguous and slippery quality of the prosthesis, that we throughout this article have tried to expand on, and as such underlines our suggestion, namely that the performative, social and collective doings (e.g. the 'sharing skills and knowledge') taking place amongst members might be viewed - with its inherent rehabilitative and compensatory but also enhancing potential in mind - as a no less prosthetic matter than any other prosthetic device (e.g. a wheelchair, a crutch, a prosthetic arm) or limb.

In addition, it is worth noting the overall popular use of the term 'integration' in relation to the prosthesis, as the final aim of any prosthesis, more often than not, is to ensure the amputee the independence needed in order to be 'integrated into society' (e.g. through promotions of equal access to and opportunities for education, work and housing). An example of this can be found in praise given to Men's Shed by the WHO stating that the organization "breaks down gender-based barriers to health-care access while integrating men as active and healthy members of their community" (WHO 2018: 70, emphasis added).

While we want to be cautious not to reduce the prosthesis to a matter of semantics, we find it important to acknowledge just how common, widespread and almost invisible the logic of the prosthesis operates. This is something a more performative-oriented approach to the prosthesis might help us to do by pointing to not only particular devices integrated in various ways into and onto the body but to the kind of social and collective health and rehabilitation activities that most of us, in some way or another, take part in on an everyday basis in order to be and feel part of a given community. Thus, paying closer attention to the various ways in which the logics of the prosthesis permeate our ways of thinking and 'doing health' may help us understand the body as it emerges in and through various forms of health practices that seek to optimize, stabilize and discipline.

\section{Concluding remarks}

In this article, we have focused on the productive capacities of broadening the scope of the concept of prosthesis. Through our engagement with different takes on the usefulness of prosthesis in a variety of academic discussions within the traditions of cultural studies and critical disability studies, we have argued that the ambiguousness of the concept fruitfully demonstrates the ways in which certain social health practices performatively enact prosthetic logics as embodied practices of prosthesis.

While this is by no means meant to be a comprehensive analysis of the ways in which prosthetic logics operate in relation to dance therapeutic practices for people with PD and group therapeutic practices in male-friendly spaces, it seems that through the lens of the prosthesis we are offered a way to critically analyze and display some of the important nuances in the negotiation and sustainment of health and embodiment in very different social settings. With our two case examples we have attempted to show that a broadened conceptualization of 
prosthesis as an integral part of certain embodied practices holds a productive potential not only in relation to disability but also when exploring forms of embodiment involved in these more general therapeutic and rehabilitating practices.

Through the duality of both the prosthesis' therapeutic and corrective properties, as well as its inherent enhancing and transformative potential, our two illustrative case examples underline the prosthesis' inevitable entanglement with health-optimizing and biomedical informed notions of prevention, rehabilitation and cure. The two examples illustrate how some health-related practices, in all their diversity, can help make visible the workings of an underlying set of values preserving and promoting individual bodily control as well as a broader societal desire for accountability, independence and autonomy. Thus, while therapeutic dance for people with PD may seek to rehabilitate 'lost' bodily skills and control, male-friendly therapeutic spaces like Men's shed aim at enhancing men's health-related competences thought to be 'missing' in the first place.

In conclusion, we have made a case for operationalizing the concept of prosthesis towards a broader spectrum of bodily and healthcare-related interventions, arguing that this does not have to be at the cost of more direct and tangible versions of prosthetic expressions and experiences. On the contrary, our hope is that our reframing of the concept can be a helpful contribution in creating more access to the productive yet often overlooked potential of the many important concepts and theories from critical disability studies.

\section{Notes}

1 See http://www.viktoriamodesta.com (Accessed on 29-08-2020).

2 See https://kunsthalcharlottenborg.dk/en/exhibitions/jesper-just/ (Accessed on 29-08-2020).

3 Dancing with Parkinson's (2019-2021) is a collaborative research project in which people with Parkinson's disease and their relatives reflect on their bodily, sensory and aesthetic experiences with dance. Based on dialogic communication theory and through the use of a variety of creative collaborative methods, the aim of the study is to co-create and share knowledge that qualifies patient-involved treatment and the use of dance as a therapeutic art activity.

The research project Medicine Man (2018-2022) explores how everyday cultures and perceptions of middle age men's bodies unfold when masculinity is increasingly both mediatized and medicalized, and is based on a theoretical framework of somatechnics and assemblage theory. The project considers medicalization as a cultural phenomenon, which emerges inseparably from contemporary media, and thus adds humanistic research to health and social sciences about how mediatized culture shapes the body and its medicalized interventions.

4 In addition to stressing the exploratory mindset of the linkages between the prosthetic logics and our chosen examples, we also want to emphasize that we are not, per se, critical toward communities and organizations whose purposes are to prevent and reduce loneliness, or to increase the quality of life for people with chronic illnesses. While being mindful about not diminishing the possibly empowering experiences of people who choose to be part of and identify with these specific practices, we do, however, find it equally important to identify and discuss the underlying logics of the ways in which such practices emerge and are being sustained.

5 The interview material from the research project Dancing with Parkinson's consists of 46 qualitative interviews conducted with PD dancers (31), relatives (8) and dance instructors (7) about their personal bodily and sensory experiences with therapeutic dancing classes for people with PD in the greater capital region in Denmark.

6 See https://au.movember.com/(Accessed on 29-08-2020).

7 See https://malehealth.org.au/(Accessed on 29-08-2019). 


\section{References}

Aguiar, L.P.C., da Rocha, P.A. \& Morris, M. 2016. Therapeutic Dancing for Parkinson's Disease. International Journal of Parkinsonism and Restless Legs Syndrome, 4, 1-25. DOI: https://doi.org/10.1016/j. ijge.2016.02.002

Al-Zubi, H. 2007. Autopathography and Audre Lorde's the Cancer Journals as a Narrative of Illness. Revising the Script of Disease. Dirasat: Human \& Social Sciences, 34, 857-870.

Barker, G., Ricardo, C., Nascimento, M., Olukoya, A. \& Santos, C. 2010. Questioning gender norms with men to improve health outcomes: evidence of impact. Glob Public Health, 5, 539-553. DOI: https://doi. org/10.1080/17441690902942464

Booher. A.K. 2010. Docile bodies, supercrips, and the plays of prosthetics. International Journal of Feminist Approaches to Bioethics (Special Issue). Disability Studies in Feminist Bioethics, 3(2), 63-89. DOI: https://doi.org/10.3138/ijfab.3.2.63

Butler, J. 1990. Gender trouble: Feminism and the subversion of identity. New York: Routledge. Cadwallader, J. \& Murray, S. 2007. Introduction. Somatechnics: Reconfiguring Body Modification (Special Issue). Social Semiotics, 17(3), 259-261. DOI: https://doi.org/10.1080/10350330701448538

Campbell, F.K. 2009. Contours of Ableism. The Production of Disability and Abledness. London: Palgrave Macmillan. DOI: https://doi.org/10.1057/9780230245181

Christensen-Stryn $\varnothing$, M.B. 2016. Mainstreaming and misfitting: Exploring disability and its intersection with gender in online disability awareness-raising videos. MedieKultur: Journal of media and communication research, 32(61), 58-75. DOI: https://doi.org/10.7146/mediekultur.v32i61.22387

Christensen-Stryn $\varnothing$, M.B. 2018. Online mediations of Disabled Embodiment. Intimacies / Mobilities / Temporalities. PhD dissertation, Department for Communication and Arts, Roskilde University.

Christensen-Stryn $\varnothing$, M.B. 2020. Writing Letters to the Dead: Cripping Networked Temporalities on Social Media. Scandinavian Journal of Disability research, 22(1), 88-96. DOI: hhtp://doi.org/10.16993/ sjdrr.627.

Christensen-Stryn $\emptyset$, M.B. \& Eriksen, C.B. 2020. Madeline Stuart as disability advocate and brand: Exploring the affective economies of social media. In: Garrisi, D. \& Johanssen, J. (eds.). Disability, Media, and Representations: Other Bodies. New York \& Abingdon: Routledge.

Christie, E. \& Bloustein, G. 2010. I-cyborg: disability, affect and public pedagogy. Discourse: Studies in the Cultural Politics of Education, 31(4), 483-498. DOI: https://doi.org/10.1080/01596306.2010.504364

Crompvoets, S. 2012. Prosthetic fantasies: loss, recovery, and the marketing of wholeness after breast cancer. Social Semiotics, 22(1), 107-120. DOI: https://doi.org/10.1080/10350330.2012.640058

Eriksen, C.B. 2017. FAT. Pop Cultural Narratives about the Fat Body. PhD dissertation, Department for the Study of Culture, University of Southern Denmark.

Ford, S., Scholz, B., \& Lu, V.N. 2015. Social shedding: Identification and health of men's sheds users. Health Psychology, 34(7), 775-778. DOI: http://dx.doi.org/10.1037/hea0000171

Forum for mænds sundhed. s.d. Om os [online]. [Accessed on 21-08-2020]: Available at: http://www. sundmand.dk/Om-os.php

Garoian, C.R. 2013. The Prosthetic Pedagogy of Art. Embodied Research and Practice. Albany, NY: State University of New York Press.

Goggin, G. \& Newell, C. 2005. Introduction: The Intimate Relations Between Technology and Disability [online]. Disability Studies Quarterly, 25(2). DOI: https://doi.org/10.18061/dsq.v25i2.547

Goodley, D. 2013. Dis/entangling critical disability studies. Disability \& Society, 28(5), 631-644. DOI: https://doi.org/10.1080/09687599.2012.717884

Golding, B. (ed.). 2015. The men's shed movement: The company of men. Champaign, Illinois: Common Ground Publishing. DOI: https://doi.org/10.18848/978-1-61229-788-0/CGP 
Grosz, E.A. 1994. Volatile bodies: Toward a corporeal feminism. Bloomington, Indiana: Indiana University Press.

Hackney, M. \& Bennett, C. 2014. Dance therapy for individuals with Parkinson's disease: improving quality of life. International Journal of Parkinsonism and Restless Legs Syndrome, 4, 17-25. DOI: https://doi. org/10.2147/JPRLS.S40042

Haraway, D. 1988. Situated knowledges: The science question in feminism and the privilege of partial perspective. Feminist studies, 14(3), 575-599. DOI: https://doi.org/10.2307/3178066

Herndl, D.P. 2002. Reconstructing the Posthuman Feminist Body Twenty Years after Audre Lorde's Cancer Journals. In: Warhol-Down, R. \& Herndl, D. P. (eds.) Feminisms REDUX: An Anthology of Literary Theory and Criticism (2009), 477-486. New Brunswick, New Jersey: Rutgers University Press

Houston, S. 2019. Dancing with Parkinson's. Bristol, UK: Intellect Ltd.

Jain, S.S. 1999. The Prosthetic Imagination: Enabling and Disabling the Prosthesis Trope. Science, Technology, \& Human Values, 24(1), 31-54. DOI: https://doi.org/10.1177/016224399902400103

Kunsthal Charlottenborg (s.d.). 2019. Jesper Just - Servitudes [online]. [Accessed on 21-08-2020]: Available at: https://kunsthalcharlottenborg.dk/en/exhibitions/jesper-just/

Lorde, A. 1980. The cancer journals. San Francisco: Aunt Lute Books.

Lupton, E., \& Miller, A. 1996. Bathroom, the Kitchen, and the Aesthetics of Waste (A Process of Elimination). Hudson, NY: Princeton Architectural Press.

Major, W. 2002. Audre Lorde's The Cancer Journals: Autopathography as Resistance. Mosaic: A Journal for the interdisciplinary Study of Literature, 35.2 (June 2002), 39-56.

McGill, A., Houston, S. \& Lee, R.Y.W. 2014. Dance for Parkinson's: A new framework for research on its physical, mental, emotional, and social benefits. Complementary Therapies in Medicine, 22(3), 426-432. DOI: https://doi.org/10.1016/j.ctim.2014.03.005

Men's shed (s.d.).What is a Men's Shed? [online]. [Accessed on 15-07-2020]: Available at: https://menssheds.org.uk/about/what-is-a-mens-shed

Mitchell, D.T. \& Snyder, S.L. 2000. Narrative Prosthesis. Disability and the Dependencies of Discourse. An Arbor: The University of Michigan Press. DOI: https://doi.org/10.3998/mpub.11523

Ott, K. 2002. The Sum of Its Parts. An Introduction to Modern Histories of Prosthetics. In: K. Ott, D. Serlin \& Mihm, S. (eds.) Artificial Parts, Practical Lives. Modern Histories of Prosthetics. New York \& London: New York University Press.

Parkinsonforeningen (s.d.). Fakta om Parkinson [online]. [Accessed on 29-08-2020]: Available at: https:// www.parkinson.dk/fakta-om-parkinson

Reeve, D. 2012. Cyborgs, cripples and iCrip: Reflections on the contribution of Haraway to disability studies. In: Goodley, D., Hughes B. \& Davis, L. (eds.) Disability and Social Theory. New Developments and Directions, US91-111. London: Palgrave Macmillan. DOI: https://doi.org/10.1057/9781137023001_6

Reiffenrath, T. 2016. Memoirs of Well-being. Rewriting Discourses of Illness and Disability. Bielefeld: Transcript Verlag. DOI: https://doi.org/10.14361/9783839435465

Sawchuk, K. 2013. Imparied. In: Adey, P, Bissell, D., Hannam, K., Merriman, P. \& Sheller, M. (eds.) The Routledge Handbook of Mobilities, 409. Taylor and Francis. ProQuest Ebook Central. [Accessed on 29-082019]: Available at: http://ebookcentral.proquest.com/lib/kbdk/detail.action?doclD=1596850.

Scarry, E. 1985. The Body in Pain: The Making and Unmaking of the World. New York \& Oxford: Oxford University Press.

Shildrick, M. 2013. Re-imagining embodiment: Prostheses, supplements and boundaries. Somatechnics, 3(2), 270-286. DOI: https://doi.org/10.3366/soma.2013.0098

Shildrick, M. 2015. Why Should Our Bodies End at the Skin?: Embodiment, Boundaries, and Somatechnics. Hypatia: A Journal of Feminist Philosophy, 30(1), 13-29. DOI: https://doi.org/10.1111/hypa.12114 Shildrick, M. 2017. Border Crossings: The Technologies of Disability and Desire. In: Waldsch- 
midt, A., Berressem, H. \& Ingwersen, M. (eds.) Culture - Theory - Disability. Encounters between Disability Studies and Cultural Studies. Bielefeld: Transcript Verlag, 137-151. DOI: https://doi. org/10.14361/9783839425336-010

Sobchack, V. 2006. A Leg to Stand On: Prosthetics, Metaphor, and Materiality. In: Smith, M. \& Morra, J. (eds.). The Prosthetic Impulse: From a Posthuman Present to a Biocultural Future, 17-41. Cambridge: MIT Press.

Sobchack, V. 2010. Living a 'Phantom Limb': On the Phenomenology of Bodily Integrity. Body \& Society, 16(3), 51-67. DOI: https://doi.org/10.1177/1357034X10373407

Sullivan, N. \& Murray, S. 2009. Somatechnics: queering the technologization of bodies. Farnham, Surrey/ Burlington, VT: Ashgate. DOI: https://doi.org/10.4324/9781315609867

Waples, E. 2013. Emplotted bodies: Breast cancer, feminism, and the future. Tulsa Studies in Women's Literature, Oct 1, 47-70.

WHO - World Health Organization. 2018. The health and well-being of men in the WHO European Region: better health through a gender approach [online]. [Accessed on 15-07-2020]: Available at: http://www. euro.who.int/en/publications/abstracts/the-health-and-well-being-of-men-in-the-who-european-regionbetter-health-through-a-gender-approach-2018

Wills, D. 1995. Prosthesis. Stanford, California: Stanford University Press. 